Magnetic Separation New.s. 1983 Vol. 1. pp. 25-36

$0731-3632 / 83 / 0101-0025 \$ 25.00 ; 0$

C. Gordon and Breach Science Publishers, Inc., 1983

Printed in the United Kingdom

MAGNETIC SEPARATION IN FINLAND

MATTI KOKKALA* and TOR MEINANDER**

* Technical Research Centre of Finland, Fire Technology Laboratory, Kivimiehentie 4, 02150 Espoo 15, Finland

** Helsinki University of Technology, Laboratory of Mineral Processing, Vuorimiehentie 2, 02150 Espoo 15, Finland

Abstract Research and development, manufacturing and industrial applications of magnetic separation in Finland are reviewed.

\title{
INTRODUCTION
}

The history of magnetic separation in Finland is rather short, being essentially limited to the period after World War II. Despite economical limitations inherent in a sparsely populated country with geographical and lingual barriers to overcome, Finland has not only applied the technology developed abroad but has also made its own contribution to the development of magnetic separators and separation methods.

This paper is a review of the most important achievements in research and development as well as in the applications of magnetic separation. The manufacturing of magnetic separators in Finland is also discussed.

\section{RESEARCH AND DEVELOPMENT}

\section{The Laurila Separator}

There is one man who has been involved in almost all activities concerning magnetic separation in Finland, namely Prof. Erkki Laurila. As a professor of technical physics (1945-1963) he developed a special interest in practical applications of magnetism and thus 
also became involved in magnetic separation. At the same time the commercial advent of ceramic ferrite magnets and the perfection of the AlNiCo's changed old patterns in the choice between permanent magnets and electromagnets for the generation of magnetic fields. Laurila was one of the first to realize the impact these new magnet materials had on the design of low intensity magnetic separators. In 1963 he was appointed a permanent member of the Academy of Finland and soon many important duties in both the public and private sector of the commercial and industrial life of Finland filled most of his time. Despite this he still retained his interest in magnetic separation and has for many years now been regarded as a father figure by most Finns active in this field. His latest patent on magnetic separators was issued only last year.

The low intensity dry magnetic separator designed and perfected by Laurila in the early 1950's, probably the most advanced of that generation of separators, employed a rotating magnet wheel inside a nonmagnetic drum rotating at a different speed ${ }^{1,2}$. The most notable of its industrial applications were the production of magnetite superconcentrates at the Höganäs iron powder plant in southern Sweden and at the Otanmäki iron ore concentrator in Finland.

Laurila later published several papers on the magnetic field distribution and the operational characteristics of separators of this kind $3,4,5$. This work was complemented by thorough experimental studies with magnetite ores carried out in the late 1950's by Urmas Runolinna ${ }^{6,7}$, later a professor at the University of Oulu.

\section{The High Intirsity Permanent Magnet Separator}

In the beginnirg of the 1970's the commercial advent of permanent magnets made of samarium-cobalt - a much more powerful magnet material than anything seen so far - made Laurila's inventive mind speculate on a new idea: Would it be possible to design a high intensity separator utilizing permanent magnets?

A preliminary study showed that all the existing electromagnetic separators were too wasteful of magnetic energy to be modi- 
fied for permanent magnet excitation. Undeterred by this Laurila went on to design a completely new kind of a separator making optimum use of the magnetic energy available in permanent magnets. Thus the HIPS (High Intensity Permanent-magnet Separator) was born. Soon it transpired that this design did not actually need the new samarium-cobalt magnets; it could be made to work with the topgrade ferrites as well. This was fortunate since pricing of samarium-cobalt (or other rare earth-cobalt) magnets has not so far made them economically attractive in high volume applications.

To demonstrate the feasibility of the HIPS-design a research project was set up by the Laboratory of Mineral Processing of the Helsinki University of Technology in collaboration with the Instrument Laboratory of the Technical Research Centre of Finland and the Engineering Division of Kone Oy (at that time the division was a
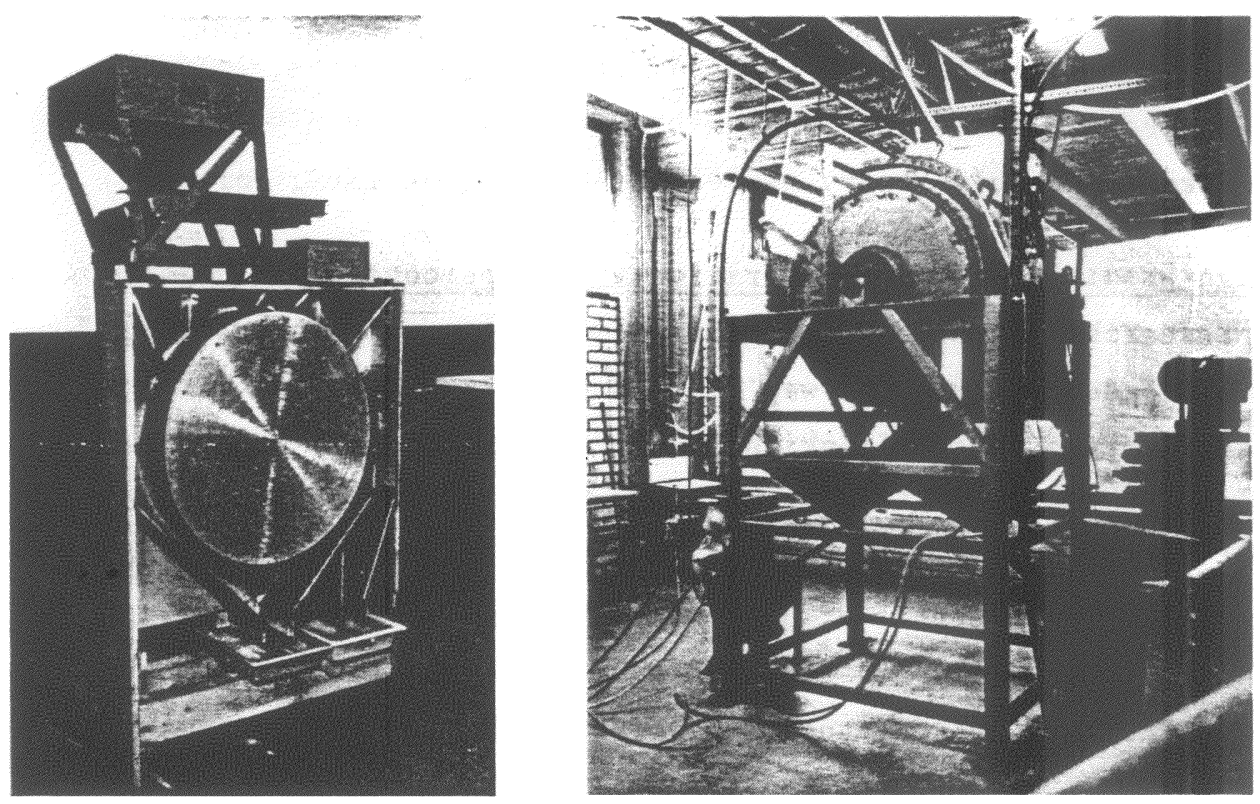

FIGURE 1 Two development steps of the HIPS separator. On the left the first prototype (1972) and on the right a pilot scale prototype (1975) set up for tests in the Laboratory of Mineral Processing. 
separate company called ROXON; this name is still retained as a trade-mark by Kone $O y$ ). Several laboratory- and pilot-scale prototypes were built, tested and modified ${ }^{10,11,12}$ until the first separator design had evolved into a whole family of separators for different applications. Today the first two generations of these separators are commercially available from Kone $0 y$ in pilot and industrial scale known as the GS- and SS-models of the HIPS. The third generation is on the drawing board and the fourth probably in the mind of Prof. Laurila.

\section{Flocculation and Demagnetization of Magnetite}

At the Otanmäki concentrator and at the University of Oulu Heikki Lantto has performed thorough studies on the magnetic flocculation of magnetite, titanomagnetite and ferrosilicon in magnetic separation processes. He showed that magnetic flocculation, once induced in a separator, shows remarkable persistence through following process steps, although these include pumping and mixing where the slurries are subjected to high shear stresses. The study also comprised deflocculation by processing in demagnetizing coils ${ }^{13}$.

High Gradient Magnetic Separation with Superconducting Magnets

A research project on high gradient magnetic separation using superconducting magnets was started in 1975 at the Low Temperature Laboratory of the Helsinki University of Technology under the leadership of Heikki Collan. The project was in the beginning carried out in collaboration with the Laboratory of Chemistry of the Technical Research Centre of Finland and funded by the Ministry of Trade and Industry and the Academy of Finland. Later as the project was continued only at the LT Laboratory the main funding was obtained from the Academy and the Maj and Tor Nessling Foundation. The project had two goals: to find out whether magnetic separation was a suitable application of superconducting magnets and to study the basic principles of high gradient magnetic separation. Two laboratory-scale superconducting magnets were designed and 


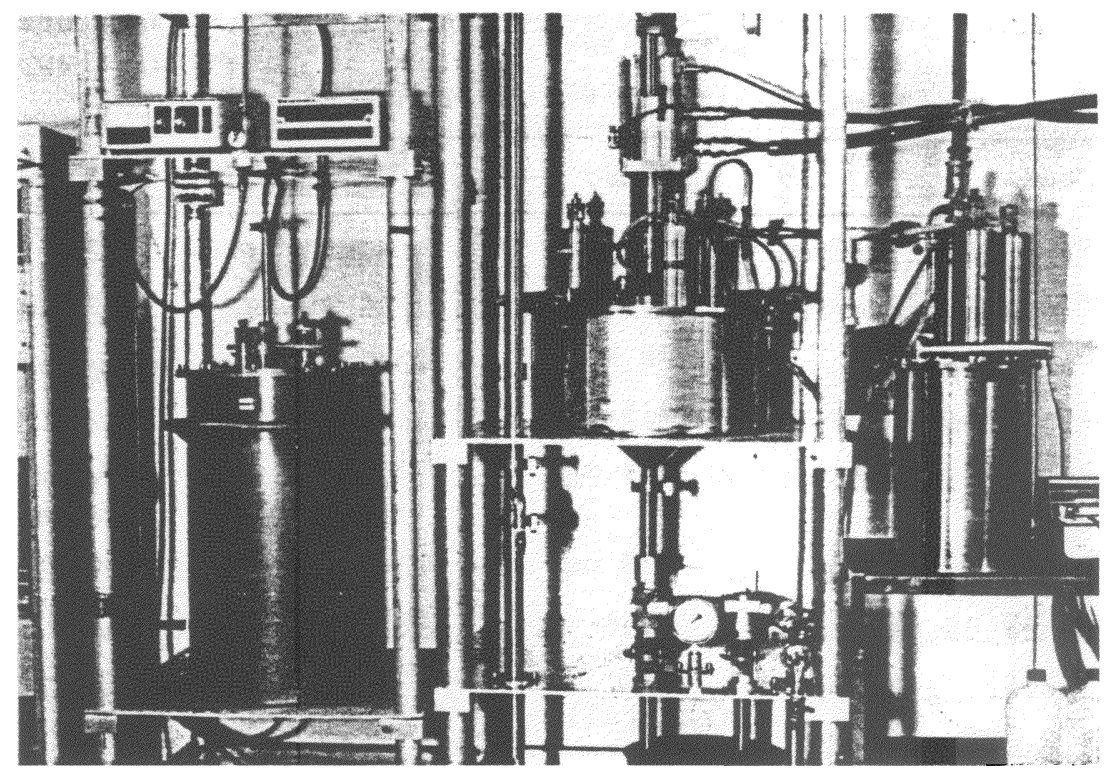

FIGURE 2 Three installations for magnetic separation studies at the Low Temperature Laboratory of the Helsinki University of Technology. The models MASU 1 (left) and MASU 2 (centre) are for high gradient and MASU 3 (right) for open gradient magnetic separation.

built (see Fig. 2) and then employed in an extensive series of laboratory and field experiments. Data on these devices are given in Table 1.

The basic research was concentrated on studies of the separation performance of various kinds of high gradient filters ${ }^{14,15}$. Mathematical methods were developed to enable a rational analysis of experiments and to extend the experimental results to process design and optimization ${ }^{16,17}$. Of the various applications studied we should mention removal of micron size carbon particles from the green liquor of a cellulose process, brightening of talc, and particularly treatment of waste waters from the Finnish steel indust$\mathrm{ry}^{18}$. In the spring of 1982 a short feasibility study of the separation of blood cells in a large blood handling process was carried out. 
TABLE I Data on the superconducting magnetic separators shown in Fig. 2 19,20. Values in parenthesis apply when the cryocooler is connected.

\begin{tabular}{llcc}
\hline Model & MASU 1 & MASU 2 & MASU 3 \\
\hline Separation method & HGMS & HGMS & OGMS \\
Cryostat material & SS 316 & SS 316 & SS 316 \\
Total weight & $56 \mathrm{~kg}$ & $48 \mathrm{~kg}(64 \mathrm{~kg})$ & $48 \mathrm{~kg}(64 \mathrm{~kg})$ \\
Liquid helium volume & 9.51 & $15.6 \mathrm{I}$ & 9.01 \\
Heat leak into 4.2 K & $115 \mathrm{~mW}$ & $210 \mathrm{~mW}$ & $180 \mathrm{~mW}$ \\
& & $(35 \mathrm{~mW})$ & $(45 \mathrm{~mW})$ \\
Solenoid length & $200 \mathrm{~mm}$ & $120 \mathrm{~mm}$ & $2 \times 85 \mathrm{~mm}$ \\
Operating current & $40 \mathrm{~A}$ & $100 \mathrm{~A}$ & $70 \mathrm{~A}$ \\
Operating field & $7 \mathrm{~T}$ & $2 \mathrm{~T}$ & $1.2 \mathrm{~T}$ \\
& (centra1) & (central) & (outside) \\
\hline
\end{tabular}

Though superconducting magnets are generally assumed to be economical only in very large systems, they have many advantages in the laboratory scale, too. The light weight and very low electrical power consumption make them easily transportable. Thus preparations for on-site experiments far away from the sheltered laboratory surroundings does not take too much time; it was demonstrated that two men taking the whole separator unit in a van are able to start experiments within one hour after arrival at the site.

\section{Superconducting Open Gradient Magnetic Separator}

As an extension to the project on HGMS, Heikki Collan and his coworkers designed and built a superconducting magnet assembly for open gradient magnetic separation ${ }^{20}$ (see Fig. 2). The magnet consists of two oppositely wound coaxial coils producing a field and a field gradient extending over a relatively large area around the cryostat. Data on this magnet (MASU 3) are given in Table 1. The separation occurs in a stream of particles that passes close to the cryostat, either falling freely in air or suspended in a pumped liquid. Splitters then divide the stream into several components 
according to the magnetic properties of the particles.

This separator has only been used for small-scale laboratory tests. However, it has been demonstrated that the principle can be used for concentration of hematite ores and for separation of apatite from pyroxenite. In the former case the magnetic minerals are recovered while in the latter case they are discarded as waste and the nonmagnetic apatite is recovered. Tests on the removal of ferromagnetic contaminants from waste waters have also shown some very promising results.

\section{INDUSTRIAL APPLICATIONS}

\section{Magnetite Beneficiation}

The largest tonnages processed by magnetic separation are generally to be found in iron ore concentration. This is true in Finland, too. In three concentrators, all belonging to the state owned steel company Rautaruukki Oy a total of 4 million tons of iron ore was treated last year, yielding about 900,000 tons of magnetite concentrates.

The smallest of these concentrators, located at Kolari in western Lapland, has a quite straightforward wet low intensity magnetic separation process recovering magnetite to be used as raw material in steel manufacturing. At the other two concentrators, serving the Otanmäki and Mustavaara mines in northern Finland, the iron in the titanomagnetite concentrates can, on the other hand, be considered more or less as a by-product of vanadium, which is leached out of the pelletized magnetic concentrates 21 . As a matter of fact, the leached out pellets from the Mustavaara process cannot be used as blast furnace feed, due to the high content of titanium.

The magnetic separation process for concentration of vanadiumbearing titanomagnetites is a very demanding one, because the leaching process requires an exceptionally pure concentrate. As mentioned before, the Otanmäki concentrator started off by using 
dry separators of the Laurila type, but later a wet process was developed. When the Mustavaara mine was opened up in 1975, the concentrator was designed along the same lines. This process is based on several stages of grinding, each followed by multistage magnetic separation, until more than $80 \%$ of the final concentrate is finer than $37 \mu \mathrm{m}$ (400 mesh). Thus, at Otanmäki there are some 60 low intensity magnetic separators of many different designs for optimum performance at different stages of the process. In the more modern Mustavaara plant the units are bigger and thus fewer separators are needed. The largest of these, having drum dimensions of $\$ 1200 \mathrm{~mm} \mathrm{x}$ L1800 mm, can handle up to 200 tons of ore per hour.

\section{Chromite Concentration}

In Kemi on the northern coast of the Gulf of Bothnia Finland's biggest mining company, Outokumpu $O y$, has operated a chromite mine since 1967. The ore reserves are extensive but of low grade, so concentration is an essential stage in the operation ${ }^{22}$. As chromite is a weakly magnetic mineral, high intensity magnetic separation was a natural choice as the principal ore dressing method. In the beginning all the concentration was done by dry separators of the induced roll type. However, low recoveries and dust problems kept those responsible for the mine on constant look-out for better solutions. Thus there was an immediate response to the advent of viable industrial-scale wet high intensity separators, and the concentration of Kemi chromite was actually the first industrial application of the large Jones separators. Eventually four of those were installed to take care of all the primary separation stages. Only finishing of high grade products is still performed dry on induced roll separators.

Although changing to wet separation did solve some problems, there still remained others that were related to the magnetic characteristics of the ore. Wide variations of the magnetic susceptibility of the chromite still caused losses at the least magnetic end 
and finely disseminated magnetite in the host rock lowered concentrate grades. Consequently advancement in another field of mineral processing - the development of an efficient high capacity gravity separator called the Reichert Cone - caused another change at the Kemi concentrator. Today gravity separation is the main method of concentration backed up by high intensity magnetic separation, wet for the finest ore fractions and dry for finishing of high grade products.

Technological development in the field of mineral processing seems to have found a hospitable playground at the Kemi concentrator. Having witnessed three different main processes during the first 15 years of operation one can but wonder what the remainder of the projected 40 years of life time will look like.

\section{Other Mineral Processing Applications}

Magnetic separation is more frequently found as a rather small step in industrial processes than as the major processing method. A few examples of such applications in the Finnish mineral processing and related industries are given below.

At the Kemiö concentrator operated by Lohja Oy, feldspar and quartz concentrates are produced by flotation of crushed pegmatite rock. For these concentrates to be acceptable as raw material for ceramics and glass, their iron content must still be lowered. This is accomplished by high intensity magnetic separation on induced roll separators, which remove the last few remaining grains of biotite, hornblende and other such "dark minerals". This kind of magnetic cleaning stage is becoming more and more common in the processing of industrial minerals, as the purer deposits are depleted.

In the Hitura concentrator of Outokumpu Oy a very difficult serpentinic nickel-copper ore is beneficiated by flotation. Among other efforts to improve the rather poor recovery of the plant, high intensity magnetic separation was tried. It was found that magnetic separation of the rougher flotation tailings gave two products that 
responded to scavenging flotation better when treated separately than in bulk. The process of the plant was modified accordingly and a $\phi 850 \mathrm{~mm} \times$ L2000 $\mathrm{mm}$ wet HIPS-GS was installed. The active mineral governing the separation is known to be finely disseminated magnetite, but the reason for the improved flotation results is not quite clear.

In a steel foundry owned by Kone Oy a HIPS-SS separator has been installed for foundry sand regeneration. Quartz and chromite sands, which are mixed when molds are broken up, can be separated again after physical regeneration of the mixture.

The examples above are rather special applications. Of course there are many other applications, e.g., the removal of tramp iron from varying process streams. These are, however, of a common nature and thus deserve no further attention in this context.

\section{Water Treatment}

The electromagnetic filters of Kraftwerk Union AG (West Germany) have been widely applied in Finland. These filters comprise an electromagnetic coil surrounding a matrix consisting of steel balls $6 \mathrm{~mm}$ in diameter. The first full-scale filter was installed for purification of paper mill condensates at Kyro Oy, Kyröskoski, some ten years ago. The capacity of this unit was $100 \mathrm{~m}^{3} / \mathrm{h}$. Since then eight more electromagnetic filters have been installed for power plant applications ${ }^{23}$. The capacity of the filters varies from $100 \mathrm{~m}^{3} / \mathrm{h}$ to $700 \mathrm{~m}^{3} / \mathrm{h}$. For example, at the Inkoo Power Station of Imatran Voima $0 y$, about $50 \mathrm{~km}$ from Helsinki, there are now four units with a capacity of $700 \mathrm{~m}^{3} / \mathrm{h}$ each.

\section{MANUFACTURING OF MAGNETIC SEPARATION EQUIPMENT}

The only company in Finland manufacturing magnetic separators of its own design is Kone Oy. The Engineering Division of Kone Oy has factories located near the town of Lahti in southern Finland, 
where both low intensity separators and high intensity HIPS separators are manufactured.

Low intensity wet separators are available in a complete series for capacities ranging from a few tons up to 350 tons per hour. Concurrent and countercurrent tanks are available. By increasing the number of magnetic poles it has been possible to optimize the magnetic field of these "high-gradient" separators to give higher magnetic forces in the working zone than those which can be achieved in most conventional separators.

Two models of the HIPS separator are manufactured, HIPS-GS featuring lower magnetic force but higher capacity of magnetics than HIPS-SS. Thus the former is preferred for the concentration of such fairly strong "paramagnetics" as hematite and ilmenite, while the latter is mainly used for removing comparatively small amounts of weakly magnetic material, e.g., to reduce the iron content of industrial mineral products. HIPS separators are usually custom-made for specific applications - both wet and dry - on the basis of pilot scale tests.

In the Otaniemi area in Espoo near Helsinki there is a concentration of technical research laboratories, a few of which have developed a considerable amount of experience in building laboratory equipment and separator prototypes for magnetic separation. At the Laboratory of Mineral Processing of the Helsinki University of Technology a range of instruments for quick small scale tests have been developed. There are also facilities for testing separator prototypes. The Instrument Laboratory of the Technical Research Centre of Finland has specialized in building prototypes of magnetic separators and other magnetic instruments. At the Low Temperature Laboratory of the Helsinki University of Technology several magnetic separators employing superconducting magnets have been designed and constructed.

Electromagnetic filters are manufactured by Sähköliikkeiden Oy (abbreviated SLO), a licencee of Kraftwerk Union AG. All the 
water treatment filters in use in Finland have been made by this company.

\section{REFERENCES}

1. E. Laurila, Stahl und Eisen, 74, 25, 1659 (1954).

2. E. Laurila, Ann. Acad. Scient. Fenn., ser. AI, 17 (1954).

3. E. Laurila, Ann. Acad. Scient. Fenn., ser. AVI, $\frac{8}{3}$ (1958).

4. E. Laurila, Ann. Acad. Scient. Fenn., ser. AIV, $\overline{3} 4$ (1959).

5. E. Laurila, Acta Pol. Scand., Ph 16 (1962).

6. U. Runolinna, Dry Magnetic Separation of Finely Ground Magnetite in a Rotating Magnetic Field, Dr.Tech. Thesis, Helsinki University of Technology (1961).

7. U. Runolinna, Progress in Mineral Dressing, Ed. by Svenska Gruvföreningen and Jernkontoret (Alqvist \& Wiksell, Stockholm, 1958), pp. 255-259.

8. E. Laurila, Acta Po1. Scand., Ph 102, (1974).

9. E. Laurila, Proc. XI Int. Mineral Proc. Congr. (Universita di Cagliari, Italy, 1975), pp. 765-775.

10. E. Laurila and T. Meinander, World Mining, 29, 12, 56 (1976).

11. T. Meinander, The Iron Ore Industry Today and Tomorrow (Univ. of Luleà, Sweden, 1978), 12 p.

12. T. Meinander, Treatment of Iron-Titanium Ores, Ed. by J. Laskowski (Polish Scientific Publishers, Warszawa, 1979) pp. 185202).

13. H. Lantto, Acta Pol. Scand., Ch 133 (1977).

14. H.K. Collan, J. Jantunen, M. Kokkala, and A. Ritvos, IEEE Trans. Magn., MAG-14, 5, 398-400 (1978).

15. H.K. Collan, J. Jantunen, M. Kokkala, and A. Ritvos, Industrial Applications of Magnetic Separation, Ed. by Y.A. Liu, IEEE Publ. No. 78CH1447-2 MAG (IEEE, New York, 1979), pp. 175-189.

16. H.K. Collan, M. Kokkala, A. Ritvos, V. Pohjola, and V. Pohjola, IEEE Trans. Magn., MAG-13, 1480-1482 (1977).

17. H.K. Collan, M.A. Kokkala, and O.E. Toikka, IEEE Trans. Magn., MAG-18, 3, 827-832 (1982).

18. H.K. Collan, M.A. Kokkala, and O.E. Toikka, Acta Pol. Scand., $\mathrm{Ph} 133$ (1982).

19. H.K. Collan, Proc. of ICEC 8 (IPC Science and Technology Press, London, 1980), Pp. 828-833.

20. H.K. Collan, M.A. Kokkala, T. Meinander, and O.E. Toikka, Trans. Instn Mining and Metallurgy, Sect C: Min. Process. Extr. Metall., 91 (March 1982).

21. E. Hokkanen and T.L. Lindholm, World Mining, 32, 7, 46 (1979).

22. T. Lukkarinen, Acta Pol. Scand., Ch 136 (1977).

23. Sähköliikkeiden Oy, private communication. 